\title{
Unmet need for family planning in Ethiopia and its association with occupational status of women and discussion to her partner: a systematic review and meta-analysis
}

\author{
Solomon Adanew Worku ${ }^{1 *}$, Yohannes Moges Mittiku ${ }^{1}$ and Abate Dargie Wubetu ${ }^{2}$
}

\begin{abstract}
Background: Unmet need refers to fecund women who either wish to postpone the next birth (spacers) or who wish to stop childbearing (limiters) but are not using a contraceptive method. Many women who are sexually active would prefer to avoid becoming pregnant but are not using any method of contraception. These women are considered to have an unmet need for family planning. Therefore, the objective of this systematic review and meta-analysis is to estimate the pooled prevalence of unmet need for family planning and its association to occupational status of women and discussion to her partner among fecund women in Ethiopia.

Method: A systemic review and meta-analysis was conducted using published and unpublished research on the prevalence of unmet need for family planning and its association to occupational status of women and discussion to her partner among fecund women in Ethiopia. Data extraction was designed in accordance with the Preferred Reporting Items for Systematic Reviews and Meta-Analyses (PRISMA) guidelines. Studies were accessed through electronic web-based search from PubMed, Cochrane Library, Google Scholar, CINAHL, and Embase. All statistical analysis were done using STATA version 14 software using random effects model. The pooled prevalence was presented in forest plots.
\end{abstract}

Results: A total of 9 studies with 9785 participants were included, and the overall pooled estimated prevalence of unmet need for family planning among fecund women in Ethiopia was 34.90\% (95\% Cl: 24.52, 45.28\%). According to subgroup analysis the estimated prevalence of unmet need for family planning in studies conducted in Amhara was 32.98\% (95\% Cl: 21.70, 44.26\%), and among married women was 32.84\% (95\% Cl: 16.62, 49.07\%). Additionally, housewife women were 1.6 times more likely have unmet need for family planning compared to government employed women (OR: 1.6, 95\% Cl: 1.29, 1.99). Moreover, women who don't discuss to partner were 1.87 times more likely to have unmet need for family planning compared to women who had discussion to her partner (OR 1.87; $95 \% \mathrm{Cl}: 1.52,2.31)$.

Conclusion: The analysis revealed that the overall prevalence of unmet need for family planning among fecund women in Ethiopia was high. Family planning programs should identify strategies to improve communication in family planning among couples and to ensure better cooperation between partners.

\footnotetext{
*Correspondence: solhabtu@gmail.com

'Department of Midwifery, College of Health Science, Debre Berhan University, P.O.Box 445, Debre Berhan, Ethiopia

Full list of author information is available at the end of the article
}



( ) The Author(s). 2020 Open Access This article is licensed under a Creative Commons Attribution 4.0 International License, which permits use, sharing, adaptation, distribution and reproduction in any medium or format, as long as you give appropriate credit to the original author(s) and the source, provide a link to the Creative Commons licence, and indicate if changes were made. The images or other third party material in this article are included in the article's Creative Commons licence, unless indicated otherwise in a credit line to the material. If material is not included in the article's Creative Commons licence and your intended use is not permitted by statutory regulation or exceeds the permitted use, you will need to obtain permission directly from the copyright holder. To view a copy of this licence, visit http://creativecommons.org/licenses/by/4.0/ The Creative Commons Public Domain Dedication waiver (http://creativecommons.org/publicdomain/zero/1.0/) applies to the data made available in this article, unless otherwise stated in a credit line to the data. 


\section{Introduction}

Unmet need refers to fecund women who either wish to delay the next birth (spacers) or who wish to stop childbirth (limiters) but are not using a contraceptive method. Many women who are sexually active would desire to avoid becoming pregnant but are not using any method of contraception. These women are measured to have an unmet need for family planning [1-3].

Sub-Saharan Africa, 25\% of women of reproductive age who are married or in a union have an unmet need for family planning. Also, four countries in Latin America and the Caribbean, eight countries in Asia and four countries in Oceania have an unmet need for family planning above $20 \%[4,5]$.

Ethiopia has among the highest levels of unmet need for contraception in Africa. The 2011 Ethiopia Demographic and Health survey (EDHS) found that $25.3 \%$ of women had unmet need for FP, $16.3 \%$ for spacing and 9\% for limiting. Unmet need for both spacing and limiting is greater among rural residents than their urban counter parts. The over-all unmet need for family planning among urban and rural residents is 15 and 27.5\% respectively [6]. Report from EDHS 2016 discloses that $58 \%$ of now married women age 15-49 have a request for family planning. Thirty-six percent of currently married women are already using a contraceptive method either to space (22\%) or to limit births (14\%). Unmet need for currently married women age 15-49 is lowermost in Addis Ababa (11\%) and maximum in Oromia region (29\%) [7].

In Ethiopia, different studies have been conducted to determine the prevalence of unmet need for family planning and associated factors. The findings of these disjointed studies familiar that there was a great inconsistency in the prevalence of unmet need for family planning across the regions of the country. Concerning associated factors, these studies revealed that different maternal and health service related factors influenced unmet need for family planning; place of residence $[8$, 9], educational status of women [9-12], occupational status of women $[8,10,12,13]$, partner educational status $[9,10]$, having a discussion to health provider $[8,10$, $14]$, and having a discussion to her partner $[10,12,13]$, were some of the factors related with unmet need for family planning. After these factors, we selected the two factors (occupational status of women and having a discussion to her partner) to see their consequence on unmet need for family planning.

Reducing the proportion of unmet need for family planning has major role in preventing maternal and child health problems. To reduce the proportion of unmet need for family planning, knowing the current level and its determinants is a prerequisite. This systematic review and meta-analysis was conducted to estimate the pooled prevalence of unmet need for family planning and its association to occupational status of women and discussion to her partner among fecund women in Ethiopia. This study can also be useful for other researchers who are interested to conduct further studies. It can also be valuable to the organization working in family planning sector to know the factors influencing unmet needs and conduct necessary programs.

\section{Methods \\ Study design and search strategy}

A systemic review and meta-analysis was conducted using published and unpublished research on the prevalence of unmet need for family planning and its association to occupational status of women and discussion to her partner among fecund women in Ethiopia. Cochrane library, PubMed, EMBASE, HINARI, and Google Scholar was systematically searched using the following terms/ phrases: "prevalence of unmet need for family planning in Ethiopia", "unmet need for family planning OR Ethiopia", "unmet need for family planning AND Ethiopia". All published and unpublished articles up to March 2019 were included in the systematic review. Additionally, we observed the reference lists of published studies to identify additional articles. Our literature search strategy, selection of publications, data extraction, and the reporting of results for the review were designed in accordance with the Preferred Reporting Items for Systematic Reviews and Meta-Analyses (PRISMA) guidelines [15].

\section{Study selection and eligibility criteria}

We included all studies that were conducted on the prevalence of unmet need for family planning among fecund women in Ethiopia. The participants were fecund women whose age is $15-49$ years. We included all study types that were published in the form of journal articles, master's thesis, and dissertations in English.

\section{Quality assessment and critical appraisal}

Qualities of each article were assessed by using a critical appraisal tool for use in systematic reviews for prevalence study [16]. The methodological quality and eligibility of the identified articles were also assessed by three reviewers (SA, YM, and $\mathrm{AD}$ ) and disagreements among reviewers were fixed accordingly with discussion. Data were extracted using pre piloted data extraction form which was developed by the authors. SA and YM conducted the primary data extraction and then SA, and $\mathrm{AD}$ examined the extracted data independently. Any disagreement and inconsistencies were resolved by discussion and consensus. 


\section{Data analysis and synthesis}

The extracted data were entered into computer through command window of STATA v.14 and the analysis was performed using STATA v.14. A random effects model was used to estimate the overall pooled prevalence. An important statistical issue in meta-analysis is handling of heterogeneity among studies. DerSimonian and Lairdmethod, which assumes heterogeneity across studies, is the most common method for using random effects model in meta-analysis [17, 18]. A random effects meta-analysis is also recommended for use when heterogeneity between studies exists. The heterogeneity of studies was checked using $I^{2}$ test statistics. $I^{2}$ statistics is used to quantify the percentage of total variation in study estimate due to heterogeneity. $I^{2}$ statistics ranges from 0 to $100 \%$. A value of $0 \%$ indicates no observed heterogeneity while $100 \%$ indicates significant heterogeneity. A $p$ value less than 0.05 was used to declare heterogeneity. In this meta-analysis, $I^{2}$ values were found to be high $(>75 \%)$. Since this value is definite indicative of significant high heterogeneity, we conducted the analysis with a random effects model with $95 \%$ CIs as opposed to the fixed effect model to adjust for the observed variability. Moreover, presence of heterogeneity was also assessed by subgroup analysis and Meta regression.

Visual assessment of publication bias was conducted using funnel plot. Asymmetry of the funnel plot is an indicator of publication bias. Egger's and Begg's tests were also conducted to check potential publication bias. A value less than 0.05 was used to declare statistical significance of publication bias. Additionally, sensitivity analysis was also done to assess whether the pooled prevalence estimates were influenced by individual studies.

\section{Results}

\section{Selection and identification of studies}

A total of 68 studies were identified from the literature search. Of these studies, 17 articles duplicate records were identified and removed. Reviewing of titles and abstracts resulted in exclusion of 31 irrelevant articles. After assessing the full texts of the remaining articles, additional 1 articles were excluded due to poor quality. Moreover, based on the inclusion and exclusion criteria for entry into the study a total of 10 studies were excluded as they did not meet the inclusion criteria. Then, a total of nine unique studies were eligible and enrolled for final analysis (Fig. 1).

\section{Characteristics of included studies}

A total of 9 studies with 9785 participants included in this meta-analysis are summarized in Table 1 . The studies were conducted from 2011 to 2019 in different region of the country. Among 9 studies five of them $[8,10$,
11, 13, 19] were conducted in Amhara, two study [14, 20] were in Tigray, and the other 2 studies [9, 12] were in other region of the country. All studies were crosssectional study conducted among married women, reproductive age women, and extended postpartum women in Ethiopia. The study with minimum and maximum sample size was conducted in Oromia and Southern Nations, Nationalities, and peoples' region, respectively $[9,12]$. In addition, out of all studies enrolled in this meta-analysis five studies $[8-10,14,19]$ were conducted among married women, three studies were conducted among reproductive age group women, while the remaining study $[11-13,20]$ were conducted among extended postpartum women (Table 1).

\section{Prevalence of unmet need for family planning}

The pooled prevalence using the fixed effect model showed significant heterogeneity between the studies. Hence, we performed the analyses using random effects model. Using random effects model, the estimated pooled prevalence of unmet need for family planning among fecund women reported by the 9 studies was $34.90 \%$ (95\% CI: 24.52, 45.28\%) with significant heterogeneity between studies $\left(I^{2}=98.9 \%, p=0.000\right)$. The pooled prevalence of unmet need for family planning presented using forest plot (Fig. 2).

Subgroup analysis by study area, and study population was conducted to assess the potential heterogeneity between studies. Of the 9 studies, the estimated unmet need for family planning prevalence found in studies conducted in Amhara (32.98\% (95\% CI: 21.70, 44.26\%), $\left.I^{2}=97.7 \%, p=0.000\right)$, and studies conducted in Tigray, was $31.53 \%\left((95 \% \mathrm{CI}: 11.54,51.52 \%), I^{2}=97.7 \%, p=\right.$ 0.000) (Fig. 3). In terms of study population, the estimated unmet need for family planning prevalence in studies conducted among married women $(32.84 \%$ (95\% CI: $\left.16.62,49.07 \%) I^{2}=99.4 \%, p=0.000\right)$, and studies conducted among reproductive age group women was $35.29 \%$ ((95\% CI: 28.86, 41.71\%), $\left.I^{2}=82.4 \%, p=0.003\right)$ (Fig. 4).

In addition, to identify the possible sources of heterogeneity univariate meta-regression was conducted by considering the sample size and year of publication as covariates. The result showed that none of them were found to be statistically significant (Table 2).

\section{Publication Bias}

Presence of publication bias was examined using funnel plots and tests (Egger's and begs). In this meta-analysis funnel plots and tests indicated evidence of publication bias. Each point in funnel plots represents a separate study and asymmetrical distribution is evidence of the existence of publication bias [21]. First, each study's effect size was plotted against the standard error and 


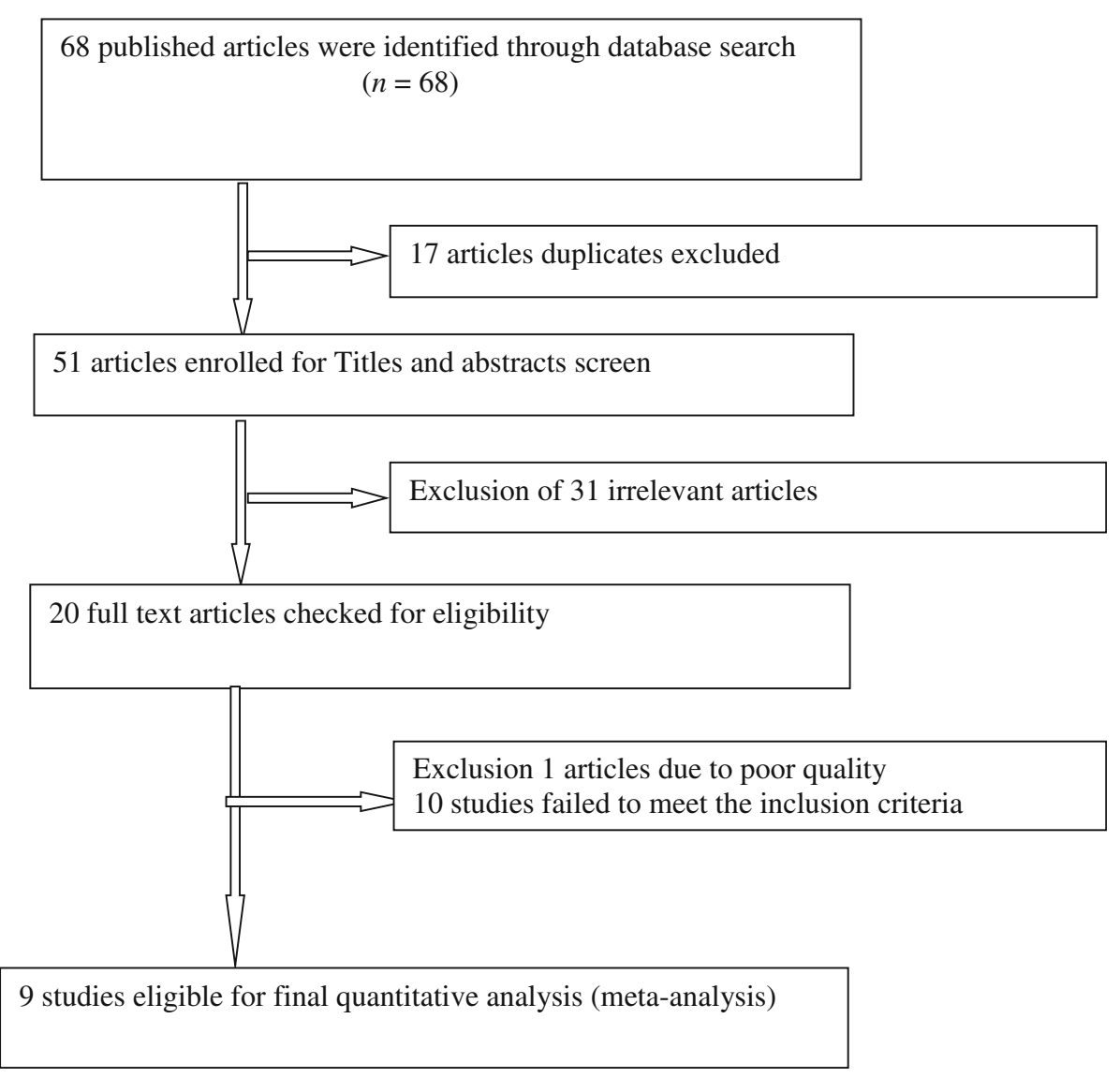

Fig. 1 Flowchart of study selection for meta-analysis of prevalence of unmet need for family planning among fecund women in Ethiopia, 2019

Table 1 Characteristics of studies included in meta-analysis of unmet need for family planning in Ethiopia and its association with occupational status of women and discussion to her partner, 2019

\begin{tabular}{|c|c|c|c|c|c|c|c|c|c|}
\hline No & $\begin{array}{l}\text { Author/s } \\
\text { (Reference) }\end{array}$ & $\begin{array}{l}\text { Year of } \\
\text { publication }\end{array}$ & $\begin{array}{l}\text { Study } \\
\text { design }\end{array}$ & $\begin{array}{l}\text { Study } \\
\text { area }\end{array}$ & $\begin{array}{l}\text { Sample } \\
\text { size }\end{array}$ & $\begin{array}{l}\text { Included } \\
\text { population }\end{array}$ & Study population & $\begin{array}{l}\text { Response } \\
\text { rate }\end{array}$ & $\begin{array}{l}\text { Prevalence } \\
\%\end{array}$ \\
\hline 1 & Genet et al. [8] & 2015 & $\begin{array}{l}\text { Cross } \\
\text { sectional }\end{array}$ & Ethiopia & 551 & 506 & Married & $99.1 \%$ & 17.4 \\
\hline 2 & Gebre et al. [14] & 2016 & $\begin{array}{l}\text { Cross } \\
\text { sectional }\end{array}$ & Ethiopia & 510 & 510 & Married & $100 \%$ & 21.4 \\
\hline 3 & $\begin{array}{l}\text { Molla and Belete } \\
\text { [19] }\end{array}$ & 2011 & $\begin{array}{l}\text { Cross } \\
\text { sectional }\end{array}$ & Ethiopia & 692 & 692 & Married & $100 \%$ & 47.3 \\
\hline 4 & $\begin{array}{l}\text { Mekonnen and } \\
\text { Worku [9] }\end{array}$ & 2011 & $\begin{array}{l}\text { Cross } \\
\text { sectional }\end{array}$ & Ethiopia & 5746 & 5746 & Married & $100 \%$ & 52.4 \\
\hline 5 & Dejenu et al. [10] & 2013 & $\begin{array}{l}\text { Cross } \\
\text { sectional }\end{array}$ & Ethiopia & 770 & 756 & Married & $98.1 \%$ & 25.6 \\
\hline 6 & Tegegn et al. [11] & 2017 & $\begin{array}{l}\text { Cross } \\
\text { sectional }\end{array}$ & Ethiopia & 383 & 382 & $\begin{array}{l}\text { Extended postpartum } \\
\text { women }\end{array}$ & $99.7 \%$ & 44 \\
\hline 7 & $\begin{array}{l}\text { Gebrecherkos et al. } \\
\text { [20] }\end{array}$ & 2018 & $\begin{array}{l}\text { Cross } \\
\text { sectional }\end{array}$ & Ethiopia & 400 & 400 & $\begin{array}{l}\text { Reproductive age } \\
\text { women }\end{array}$ & $100 \%$ & 41.8 \\
\hline 8 & Mota et al. [12] & 2015 & $\begin{array}{l}\text { Cross } \\
\text { sectional }\end{array}$ & Ethiopia & 382 & 382 & $\begin{array}{l}\text { Reproductive age } \\
\text { women }\end{array}$ & $100 \%$ & 33.3 \\
\hline 9 & Worku et al. [13] & 2019 & $\begin{array}{l}\text { Cross } \\
\text { sectional }\end{array}$ & Ethiopia & 411 & 411 & $\begin{array}{l}\text { Reproductive age } \\
\text { women }\end{array}$ & $100 \%$ & 30.9 \\
\hline
\end{tabular}


Study

ID

ES $(95 \% \mathrm{Cl})$



Fig. 2 Forest plot showing the pooled prevalence of unmet need for contraceptive among fecund women in Ethiopia, 2019

visual inspection of the funnel plot suggests some asymmetry, as six studies lay on the left side and three studies on the right side of the line representing the pooled prevalence (Fig. 5). We also performed Egger's and Begg's tests to investigate publication bias. The result of these tests showed significant evidence of publication bias ( $p$ value $<0.05)$.

\section{Sensitivity analysis}

The result of sensitivity analysis using random effects model suggested that no single study unduly influenced the overall prevalence estimate of unmet need for family planning among fecund women (Fig. 6).

\section{Association between occupational status of women and unmet need for family planning}

In this meta-analysis, we examined the association between women occupation and unmet need for family planning by using four available studies [8, 10, 12, 13]. The findings from these four studies revealed that the unmet need for family planning was significantly associated with women occupation. Accordingly, the likelihood of unmet need for family planning was 1.6 times higher among house wife as compared to women's who have government employed (OR: 1.6, 95\% CI: 1.29, 1.99). High heterogeneity $\left(\mathrm{I}^{2}=76.7 \%\right.$ and $p$ value $\left.<0.005\right)$ was observed across the included studies; hence, a random effect meta-analysis model was used to examine the association between women's occupation and unmet need for family planning. For this analysis, we also assessed publication bias using Begg's and Egger's tests, the result of the test statistics indicated that there was no possible presence of statistically significant publication bias $(p=0.174$ and $(p=0.132)$ respectively.

\section{Association between women discussion with her partner and unmet need for family planning}

Three studies, which examined the association between women discussion with her partner and unmet need for family planning were considered to determine the association between unmet need for family planning and 


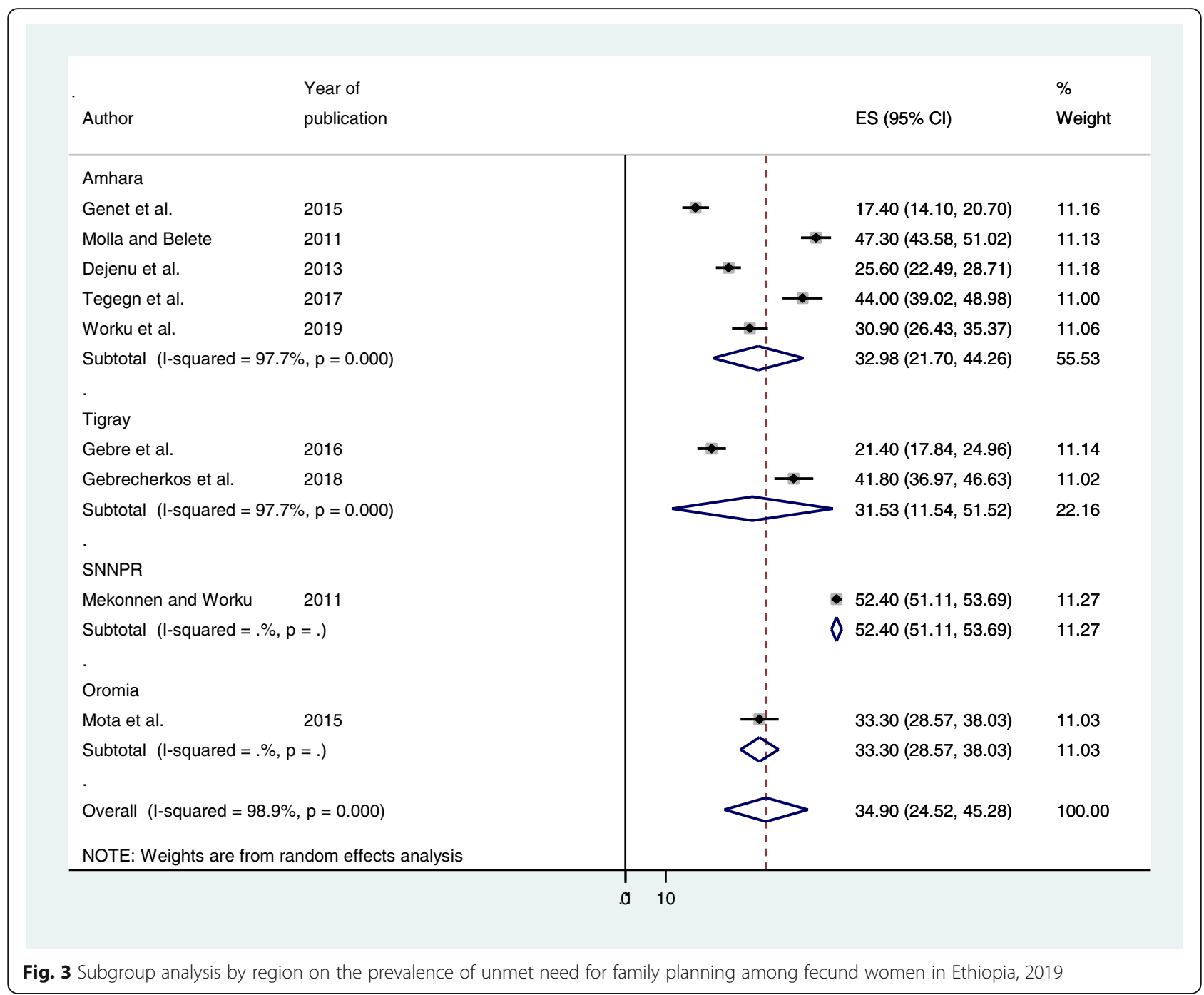

women discussion with her partner $(10,1213)$. In this study, the pooled odds ratio indicated that women discussion with her partner was positively associated with unmet need for family planning (OR: $1.87,95 \% \mathrm{CI}: 1.52$, 2.31). In this meta-analysis, high heterogeneity $\left(I^{2}=\right.$ $64.9 \%$ and $p$ value $<0.036$ ) was observed across the studies hence, a random effect meta-analysis model was employed to estimate the pooled effect. We also assessed publication bias using Begg's and Egger's tests, the result of the test statistics indicated that there was no possible presence of statistically significant publication bias $(p=0.497$ and $(p=0.433)$ respectively.

\section{Discussion}

We conducted this systematic review and meta-analysis to estimate the pooled prevalence of unmet need for family planning in Ethiopia and its association with occupational status of women and discussion to her partner. The pooled prevalence of unmet need for family planning in Ethiopia was $34.90 \%$ (95\% CI: 24.52, 45.28\%). The overall prevalence indicated in this metaanalysis is similar the study conducted in Burundi (32.4\%), and Nagpur city in India (31.6\%) [21, 22]. In addition, this finding is higher than the study conducted in Botswana (9.6\%), rural Burkina Faso (18.26\%), Urban Cameroon (20.4\%), Zambia (25.5\%), Nnewi, south-east Nigeria (21.4\%), and Bangladesh (22.4\%) [22-27]. On the other hand, our finding is lower than the study conducted in Eastern Sudan (44.8\%.), Angola (51.7\%), North West Region, Cameroon (46.6\%), Kenya (46\%), Guatemala (67.6\%), India Belgaum (64\%), Pakistan (96.6\%), and Nepal during the first 2 years postpartum (52\%) [22, 28-32]. The possible explanations for the above variations could be due to methodological differences (sampling of study participants), and health service utilization. 


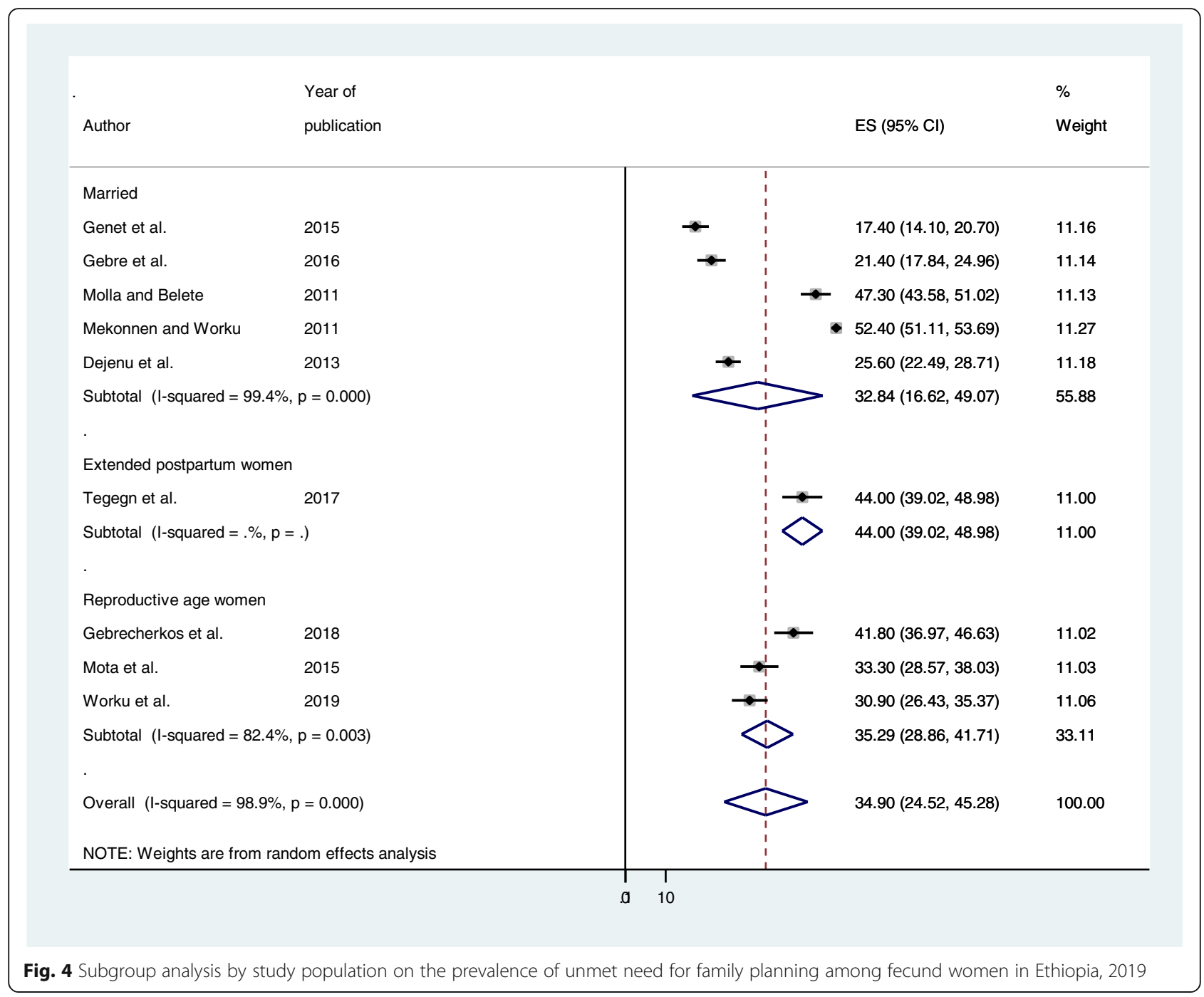

We also performed subgroup analysis by study area, and study population was conducted to assess the potential heterogeneity between studies. The estimated unmet need for family planning prevalence found in studies conducted in Amhara (32.98\%), and studies conducted in Tigray, was $31.53 \%$. In terms of study population, the estimated unmet need for family planning prevalence in studies conducted among married women (32.84\%), and studies conducted among reproductive age group women was $35.29 \%$.

Table 2 Meta-regression analysis of factors with heterogeneity of the prevalence of unmet need for family planning among fecund women in Ethiopia, 2019

\begin{tabular}{llll}
\hline Heterogeneity source & Coefficients & Std. err. & value \\
\hline Sample size & 0.0035064 & 0.002933 & 0.277 \\
Publication year & -0.1702263 & 1.804313 & 0.928 \\
\hline
\end{tabular}

The current meta-analysis was also examined the association between women discussion with her partner and unmet need for family planning, and association between occupational status of women and unmet need for family planning in Ethiopia. Accordingly, women discussion with her partner was positively associated with unmet need for family planning, and occupational status of women was positively associated with unmet need for family planning. Women who had not a discussion with her partner were almost 1.87 times more likely to have unmet need for family planning as compared to women who had a discussion to her partner. This finding is consistent with the studies conducted in Botswana [23], Urban Cameroon [25], and North West Region, Cameroon [30]. This could be due to the fact that couples where both partners reported communicating with each other regarding desired number of children and 


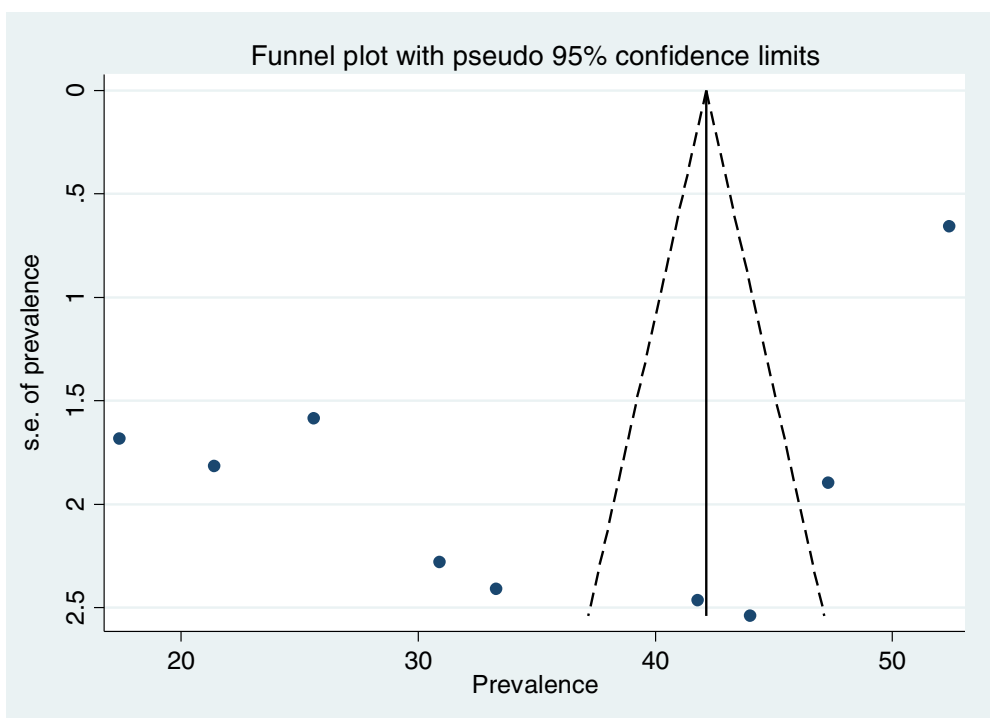

Fig. 5 Funnel plots to test the publication bias of the 9 studies, 2019

family planning use were more likely to use contraception compared to couples that did not communicate. Spousal communication regarding family planning would be an effective way to motivate partner for supporting and using contraceptives [33]. Unmet need for family planning is higher among housewife women than among government employed women. Women who are housewife were almost 1.6 times more likely to have unmet need for family planning as compared to government employed women. This finding is in agreement with studies conducted in Eastern Sudan [28]. The reason for this may be due to economic and educational concern. Housewives do not have their own monthly income and they are dependent on their partner. Due to this, they may believe that they can't afford expenses to use contraceptive methods. A woman's educational attainment has the greatest impact on her contraceptive behavior.



Fig. 6 Result of Sensitivity analysis of the 9 studies, 2019 


\section{Conclusion and recommendation}

The overall prevalence of unmet need for family planning among fecund women in Ethiopia was high. Women occupational status and have a discussion with her partner were significantly associated with unmet need for family planning. Family planning programs should identify strategies to improve communication in family planning among couples and to ensure better cooperation between partners.

\section{Acknowledgments}

The authors would like to thank all authors of studies included in this systematic review and meta-analysis.

\section{Authors' contributions}

SAW, YMM, and ADW developed the protocol and was involved in the design, selection of study, data extraction, and statistical analysis and developing the initial drafts of the manuscript. SAW, and YMM prepared the final draft of the manuscript. All authors read and approved the final draft of the manuscript.

\section{Funding}

Not applicable.

\section{Availability of data and materials}

Data will be available upon request of the corresponding author.

\section{Ethics approval and consent to participate}

Not applicable.

\section{Consent for publication}

Not applicable.

\section{Competing interests}

The authors declare that they have no conflicts of interest.

\section{Author details}

'Department of Midwifery, College of Health Science, Debre Berhan University, P.O.Box 445, Debre Berhan, Ethiopia. ${ }^{2}$ Department of Nursing, College of Health Science, Debre Berhan University, Debre Berhan, Ethiopia.

Received: 1 November 2019 Accepted: 6 September 2020

Published online: 20 November 2020

\section{References}

1. Lata K, Barman SK, Ram R, Mukherjee S, Ram AK. Prevalence and determinants of unmet need for family planning in Kishanganj district, Bihar, India. Glob J Med and Pub Health. 2012;1(4):29-33.

2. Shifa GT, Kondale M. High unmet need for family planning and factors contributing to it in southern Ethiopia: A community-based cross-sectional study. Global Journal of Medical Research. 2014;14:20-32.

3. Bhattacharya SK, Ram R, Goswami DN, Gupta UD, Bhattacharya K, Ray S. Study of unmet need for family planning among women of reproductive age group attending immunization clinic in a medical college of Kolkata. Indian J Community Med. 2006;31(2):73-5.

4. Tiwari S. Factors influencing unmet needs for family planning among currently married women in Nepal: Universitetet i Tromsø; 2012.

5. Lawn JE, Kinney MV, Belizan JM, Mason EM, McDougall L, Larson J, Lackritz E, Friberg IK, Howson CP. Born too soon: accelerating actions for prevention and care of 15 million newborns born too soon. Reprod Health. 2013;10(1):S6

6. Ethiopia CS. ICF international. Ethiopia demographic and health survey. 2011.

7. Central Statistics Agency. Report of 2016 Ethiopian Demographic andHealth Survey (EDHS). 2017

8. Genet $\mathrm{E}$, Abeje G, Ejigu T. Determinants of unmet need for family planning among currently married women in Dangila town administration, Awi zone, Amhara regional state; a cross sectional study. Reprod Health. 2015;12(1):42.
9. Mekonnen W, Worku A. Determinants of low family planning use and high unmet need in Butajira District, South Central Ethiopia. Reprod Health. 2011; 8(1):37.

10. Dejenu G, Ayichiluhm M, Abajobir AA. Prevalence and associated factors of unmet need for family planning among married women in Enemay District, Northwest Ethiopia: a comparative cross-sectional study. Global J Med Res. 2013;13(4).

11. Tegegn M, Arefaynie M, Tiruye TY. Unmet need for modern contraceptives and associated factors among women in the extended postpartum period in Dessie town, Ethiopia. Contracept Reprod Med. 2017;2(1):21.

12. Mota K, Reddy S, Getachew B. Unmet need of long-acting and permanent family planning methods among women in the reproductive age group in shashemene town, Oromia region, Ethiopia: a cross sectional study. BMC Womens Health. 2015;15(1):51.

13. Worku SA, Ahmed SM, Mulushewa TF. Unmet need for family planning and its associated factor among women of reproductive age in Debre Berhan town, Amhara, Ethiopia. BMC research notes. 2019;12(1):143.

14. Gebre G, Birhan N, Gebreslasie K. Prevalence and factors associated with unmet need for family planning among the currently married reproductive age women in Shire-Enda-Slassie, Northern West of Tigray, Ethiopia 2015: a community based cross-sectional study. Pan Afr Med J. 2016:23(1):1-9.

15. Liberati A, Altman DG, Tetzlaff J, Mulrow C, Gøtzsche PC, loannidis JP, Clarke M, Devereaux PJ, Kleijnen J, Moher D. The PRISMA statement for reporting systematic reviews and meta-analyses of studies that evaluate health care interventions: explanation and elaboration. PLoS Med. 2009;6(7):e1000100.

16. Munn Z, Moola S, Riitano D, Lisy K. The development of a critical appraisal tool for use in systematic reviews addressing questions of prevalence. Int J Health Policy Manag. 2014;3(3):123.

17. George BJ, Aban IB. An application of meta-analysis based on DerSimonian and Laird method. Springer; 2016.

18. IntHout J, loannidis JP, Borm GF. The Hartung-Knapp-Sidik-Jonkman method for random effects meta-analysis is straightforward and considerably outperforms the standard DerSimonian-Laird method. BMC Med Res Methodol. 2014:14(1):25.

19. Molla G, Belete H. Unmet need for family planning and its determinants among currently married women in Kobbo woreda, North-East of Amhara. Ethiop J Reprod Health. 2011;5(1)

20. Gebrecherkos K, Gebremariam B, Gebeyehu A, Siyum H, Kahsay G, Abay M. Unmet need for modern contraception and associated factors among reproductive age group women in Eritrean refugee camps, Tigray, North Ethiopia: a cross-sectional study. BMC Res Notes. 2018; 11(1):851.

21. Nzokirishaka A, Itua I. Determinants of unmet need for family planning among married women of reproductive age in Burundi: a cross-sectional study. Contracept Reprod Med. 2018:3(1):11.

22. Pasha O, Goudar SS, Patel A, Garces A, Esamai F, Chomba E, Moore JL, Kodkany BS, Saleem S, Derman RJ, Liechty EA. Postpartum contraceptive use and unmet need for family planning in five low-income countries. Reprod Health. 2015;12(2):S11.

23. Letamo G, Navaneetham K. Levels, trends and reasons for unmet need for family planning among married women in Botswana: a cross-sectional study. BMJ Open. 2015;5(3):e006603.

24. Wulifan JK, Jahn A, Hien H, Ilboudo PC, Meda N, Robyn PJ, Hamadou TS, Haidara O, De Allegri M. Determinants of unmet need for family planning in rural Burkina Faso: a multilevel logistic regression analysis. BMC Pregnancy Childbirth. 2017;17(1):426.

25. Ajong AB, Njotang PN, Yakum MN, Essi MJ, Essiben F, Eko FE, Kenfack B, Mbu ER. Determinants of unmet need for family planning among women in urban Cameroon: a cross sectional survey in the Biyem-Assi Health District, Yaoundé. BMC Womens Health. 2015;16(1):4.

26. Anthony Ol, Joseph OU, Emmanuel NM. Prevalence and determinants of unmet need for family planning in Nnewi, south-East Nigeria. Int J Med Med Sci. 2009;1(8):325-9.

27. Ferdousi SK, Jabbar MA, Hoque SR, Karim SR, Mahmood AR, Ara R, Khan NR. Unmet need of family planning among rural women in Bangladesh. J Dhaka Med Coll. 2010;19(1):11-5.

28. Ali AA, Okud A. Factor's affecting unmet need for family planning in eastern Sudan. BMC Public Health. 2013:13(1):102.

29. Yaya S, Ghose B. Prevalence of unmet need for contraception and its association with unwanted pregnancy among married women in Angola. PLoS One. 2018;13(12):e0209801. 
30. Edietah EE, Njotang PN, Ajong AB, Essi MJ, Yakum MN, Mbu ER. Contraceptive use and determinants of unmet need for family planning; a cross sectional survey in the north west region, Cameroon. BMC Womens Health. 2018:18(1):171.

31. Mehata S, Paudel YR, Mehta R, Dariang M, Poudel P, Barnett S. Unmet need for family planning in Nepal during the first two years postpartum. Biomed Res Int. 2014;2014.

32. Najafi-Sharjabad F, Hejar Abdul Rahman MH, Yahya SZ. Spousal communication on family planning and perceived social support for contraceptive practices in a sample of Malaysian women. Iran J Nurs Midwifery Res. 2014;19(7 Suppl 1):S19.

33. Egger M, Smith GD, Schneider M, Minder C. Bias in meta-analysis detected by a simple, graphical test. BMJ. 1997;315(7109):629-34.

\section{Publisher's Note}

Springer Nature remains neutral with regard to jurisdictional claims in published maps and institutional affiliations.

Ready to submit your research? Choose BMC and benefit from:

- fast, convenient online submission

- thorough peer review by experienced researchers in your field

- rapid publication on acceptance

- support for research data, including large and complex data types

- gold Open Access which fosters wider collaboration and increased citations

- maximum visibility for your research: over $100 \mathrm{M}$ website views per year

At BMC, research is always in progress.

Learn more biomedcentral.com/submissions 